
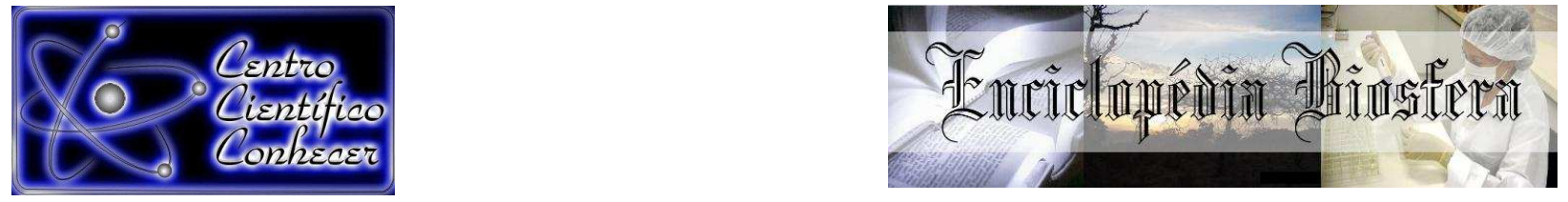

\title{
AVALIAÇÃO DA EFICIÊNCIA DO PPHO DE UM MATADOURO FRIGORÍFICO BOVINO DE RONDÔNIA - ESTUDO DE CASO
}

\author{
Nahuanna Vieira Valeiro ${ }^{1}$; Aline Pedrosa de Oliveira ${ }^{2}$; Lara Covre ${ }^{2}$; Celina \\ Martins Decol ${ }^{2}$; Jussara de Araújo Gonçalves ${ }^{3}$
}

1 Discente do Curso de Engenharia de alimentos, Faculdade de Arquitetura e Engenharia, Universidade do Estado de Mato Grosso - UNEMAT, Barra do Bugres, Mato Grosso, Brasil

2 Docente, Mestre, Faculdade de Arquitetura e Engenharia, Departamento de Engenharia de Alimentos, Universidade do Estado de Mato Grosso - UNEMAT, Barra do Bugres, Mato Grosso, Brasil

3 Docente, Doutora, Faculdade de Arquitetura e Engenharia, Departamento de Engenharia de Alimentos, Universidade do Estado de Mato Grosso - UNEMAT, Barra do Bugres, Mato Grosso, Brasil

*Endereço para correspondência: aline pdo@hotmail.com

Recebido em: 08/09/2015 - Aprovado em: 14/11/2015 - Publicado em: 01/12/2015 DOI: http://dx.doi.org/10.18677/Enciclopedia_Biosfera_2015_094

\section{RESUMO}

Foi avaliada a eficiência do Procedimento Padrão de Higiene Operacional (PPHO) realizado durante o intervalo de almoço de um matadouro frigorífico bovino localizado no estado de Rondônia. Para tanto, analisou-se 24 superfícies de equipamentos e utensílios de diferentes setores da indústria, tanto da área fria como da área quente. As amostras foram coletadas por meio de suabes de superfície antes e depois da realização do PPHO do intervalo de almoço, para realização da contagem de mesófilos aeróbios em placas petrifilm $\AA A C$, durante quatro semanas consecutivas. Foram encontradas em todas as superfícies médias de contagem entre 0 e 69 UFC/ $\mathrm{cm}^{2}$ antes do procedimento de higienização no intervalo de almoço e médias inferiores a $6 \mathrm{UFC} / \mathrm{cm}^{2}$ após a higienização. As contagens observadas após o PPHO mostraram-se de acordo com o limite máximo estabelecido pelo regulamento 2073 de 2005 da Comissão das Comunidades Europeias, comprovando a eficiência do procedimento realizado durante o intervalo de almoço.

PALAVRAS-CHAVE: análise microbiológica, equipamentos, mesófilos aeróbios, utensílios

\section{SSOP EFFICIENCY EVALUATION IN A BOVINE REFRIGERATOR SLAUGHTERHOUSE IN STATE OF RONDÔNIA}

\begin{abstract}
Efficiency of Sanitation Standard Operating Procedure (SSOP) was evaluated during the break lunch time in a refrigerator slaugtherhouse located in the state of Rondônia. Likewise, 24 surfaces of equipment and utensils from different industry sectors were analyzed, in both areas, cold and hot. Samples were collected during four consecutive weeks by surface swabs before and after of SSOP done in the lunch break time to counting aerobic mesophilic on petrifilm®AC plate. Counting
\end{abstract} ENCICLOPÉDIA BIOSFERA, Centro Científico Conhecer - Goiânia, v.11 n.22; p.408 2015 
means were detected between 0 and $69 \mathrm{CFU} / \mathrm{cm}^{2}$ for all surfaces before the cleanig procedure at the time of lunch break and means lower than $6 \mathrm{CFU} / \mathrm{cm}^{2}$ after cleaning. Counting observed after SSOP were in accordance with the higher limit established by regulation 2073 from Commission of the European Communities (2005), proving the efficiency of the procedure performed during the lunch break time.

KEYWORDS: aerobic mesophilic, equipment, microbiological analysis, utensils

\section{INTRODUÇÃO}

Estimou-se que em 2013 a produção mundial de carnes bovina alcançou 57.527 milhões de toneladas. O Brasil ocupa o segundo lugar deste ranking, perdendo somente para os Estados Unidos da América (CONAB, 2014). No ano de 2013, o país produziu aproximadamente nove milhões de toneladas de carne bovina, exportando mais de 1600 milhões de toneladas, o que gerou receita próxima de 11 bilhões de reais. Além dos lucros com as exportações, o Brasil apresenta um forte mercado interno, sendo os brasileiros um dos maiores consumidores de carne bovina, com consumo em torno de 37 quilos per capita/ano, absorvendo $85 \%$ da produção (IBGE, 2013; BRASIL, 2014; CONAB, 2014).

Durante muito tempo a garantia da qualidade era um diferencial de algumas empresas, porém, a qualidade e segurança tornaram-se condição indispensável para a manutenção do produto no mercado. A contaminação de um alimento pode gerar prejuízos, pois os consumidores optam por não adquirir produtos associados a algum tipo de problema. Portanto, a competição por mercado e consumidores cada vez mais exigentes e conscientes de seus direitos tornam a qualidade dos produtos sinônimo de sobrevivência da empresa (OLIVEIRA et al., 2009).

Os produtos de origem animal são de fácil contaminação. A carne bovina pode ser contaminada durante e após as operações de abate, ocorrendo de forma direta, indireta ou cruzada, causando alterações no valor nutricional e nas características sensoriais, além de trazer risco à saúde do consumidor. As operações de sangria, esfola, evisceração, corte e desossa merecem atenção especial, pois são responsáveis pela maior incidência de contaminação (BORGES \& FREITAS, 2002).

A principal forma de controle na produção de alimentos é feita por meio da adoção de programas como as Boas Práticas de Fabricação (BPFs), o sistema de Análise de Perigos e Pontos Críticos de Controle (APPCC) e o Procedimento Padrão de Higiene Operacional (PPHO). Sendo estes recomendados pelo Ministério da Agricultura, Pecuária e Abastecimento (MAPA) e Ministério da Saúde (MS) (OLIVEIRA et al., 2009).

A higiene adequada da indústria é um fator preponderante para a garantia da inocuidade e a qualidade do produto final, uma vez que falhas na higienização de equipamentos, utensílios e manipuladores, podem ocasionar surtos de doenças de origem microbiológicas (JAY, 2005).

O Procedimento Padrão de Higiene Operacional foi criado para que se tenha controle sobre a correta higienização dos equipamentos e utensílios utilizados no processo de produção da carne bovina, evitando a contaminação cruzada, garantindo assim a inocuidade e, consequentemente, a segurança alimentar (PASTRO, 2012).

Diante do exposto, nota-se a importância da verificação do Procedimento Padrão de Higiene Operacional das superfícies da área de produção de um matadouro-frigorífico bovino, em virtude das frequentes não conformidades ocorridas 
durante o processo de obtenção da carne bovina, e da emergente necessidade da garantia da qualidade tendo em vista a relevância no cenário nacional e internacional.

Portanto, objetivou-se com este trabalho avaliar a eficácia dos procedimentos de higiene operacional de superfícies aplicados durante o intervalo de almoço, nas áreas de produção quente e fria de um matadouro frigorífico.

\section{MATERIAL E MÉTODOS}

\section{Verificação da higienização dos equipamentos e utensílios}

Foi procedida a verificação da higienização dos equipamentos e utensílios durante o intervalo de almoço em um matadouro frigorífico. A higienização nos setores de matança, miúdos, bucharia limpa, triparia e sala de cortes foi realizada retirando-se os resíduos grosseiros manualmente e descartando-os em bandejas vermelhas e/ou encaminhando-os por chutes ao setor de subprodutos. Posteriormente, aplicou-se água de no mínimo $82,5^{\circ} \mathrm{C}$ por meio de jatos sob pressão até que os resíduos orgânicos fossem completamente removidos.

No setor de desossa, os procedimentos de higienização foram realizados retirando-se os resíduos grosseiros manualmente, sendo estes descartados em bandejas vermelhas e encaminhados ao setor de subprodutos. Em seguida, com o auxilio de um pano perfex as superfícies dos equipamentos foram esfregadas e aplicou-se sanitizante a base de Ácido Peracético (Divisan Forte da Diversey®)com concentração mínima de 14\%.

\section{Coleta de amostras}

Para avaliar a eficiência dos procedimentos de limpeza e sanitização, foram coletadas amostras antes e após a realização da higienização do período de intervalo de almoço. As amostras foram coletadas por meio de suabes de superfície em 24 pontos, sendo 14 pontos na área fria e 10 pontos na área quente como podese observar nos Quadros 1 e 2. As coletas foram realizadas uma vez por semana durante quatro semanas consecutivas, totalizando 192 amostras, durante o mês de setembro de 2014.

QUADRO 1 - Pontos de coleta da área fria de um matadouro frigorífico, realizadas durante quatro semanas consecutivas em setembro de 2014.

\begin{tabular}{|l|l|l|}
\hline \multirow{4}{*}{} & Setor & Ponto de Coleta \\
\cline { 2 - 3 } & Desossa & Mesa de desossa do traseiro A \\
\cline { 2 - 3 } Frea & Desossa & Mesa de desossa do traseiro B \\
\cline { 2 - 3 } & Desossa & Mesa de desossa do dianteiro A \\
\cline { 2 - 3 } & Desossa & Mesa de desossa do dianteiro B \\
\cline { 2 - 3 } & Desossa & Mesa de refile do traseiro A \\
\cline { 2 - 3 } & Desossa & Mesa de refile do traseiro B \\
\cline { 2 - 3 } & Desossa & Mesa de refile do dianteiro A \\
\cline { 2 - 3 } & Desossa & Mesa de refile do dianteiro B \\
\cline { 2 - 3 } & Desossa & Mesa de embalagem primária do traseiro A \\
\cline { 2 - 3 } & Desossa & Mesa de embalagem primária do traseiro B \\
\cline { 2 - 3 } & Desossa & Mesa de embalagem primária do dianteiro A \\
\cline { 2 - 3 } & Desossa & Mesa de embalagem primária do dianteiro B \\
\cline { 2 - 3 } & Corte & Serra de quartos \\
\hline
\end{tabular}


QUADRO 2 - Ponto de Coleta da área quente de um matadouro frigorífico, realizadas durante quatro semanas consecutivas em setembro de 2014.

\begin{tabular}{|l|l|l|}
\hline \multirow{4}{*}{} & Setor & Ponto de Coleta \\
\cline { 2 - 3 } & Abate & Mesa de vísceras \\
\cline { 2 - 3 } Quea & Abate & Mesa da cabeça \\
\cline { 2 - 3 } & Abate & Serra de peito \\
\cline { 2 - 3 } & Abate & Esfoladeira \\
\cline { 2 - 3 } & Triparia & Máquina de escorrer tripa \\
\cline { 2 - 3 } & Triparia & Mesa de refilar tripa \\
\cline { 2 - 3 } & Miúdos & Mesa de embalar miúdos \\
\cline { 2 - 3 } & Miúdos & Centrífuga de miúdos \\
\cline { 2 - 3 } & Bucharia & Centrífuga de buchos \\
\cline { 2 - 3 } & Bucharia & Tanque de resfriamento de buchos \\
\hline
\end{tabular}

Foram utilizados gabaritos de $4 \times 5 \mathrm{~cm}$, previamente esterilizados, posicionados sob as superfícies, friccionando a um ângulo de aproximadamente $45^{\circ}$ com movimentos de rotação na horizontal e na vertical. Logo após, os suabes foram transferidos para bolsas estéreis tipo stomacher contendo um $\mathrm{mL}$ do meio de cultura SSP (Solução Salina Peptonada 0,1\%), as quais foram lacradas e devidamente identificadas.

As amostras foram acondicionadas em caixas isotérmicas com gelox (gelo reciclável) para manutenção da temperatura entre 0 e $4^{\circ} \mathrm{C}$ e enviadas imediatamente ao laboratório de análises microbiológicas, localizado na própria indústria, para análise de contagem total de mesófilos aeróbios conforme metodologia proposta AOAC (2007).

\section{Pesquisa de mesófilos}

Foram adicionados às amostras $40 \mathrm{~mL}$ de SSP, e homogeneizados por aproximadamente dois minutos, com auxílio do misturador tipo stomacher. Para a contagem de micro-organismos aeróbios mesófilos, foram utilizadas placas petrifilm® $A C$, nas quais foram transferidas alíquotas de um $\mathrm{mL}$ da solução salina inoculada.

Após a inoculação, o petrifilme foi fechado para evitar a entrada de ar e a amostra foi distribuída de maneira uniforme sobre a placa com auxílio de um difusor plástico. Terminada a inoculação das placas, as mesmas permaneceram em repouso por pelo menos um minuto para permitir a solidificação do gel e, em seguida, foram incubadas à $35^{\circ} \mathrm{C} \pm 1^{\mathrm{C}} \mathrm{C}$ na posição horizontal, com $\mathrm{o}$ lado transparente para cima.

Transcorrido o período de incubação, foram selecionadas placas com até 300 colônias, para contagem total de micro-organismos aeróbios mesófilos com auxílio de contador de colônias Quebec. Foram contabilizadas as colônias que apresentaram coloração vermelha, independente do tamanho ou intensidade e o resultado foi expresso em $U F C / \mathrm{cm}^{2}$. O valor da contagem das colônias foi multiplicado por 2 que corresponde à alíquota inoculada e a área por $\mathrm{cm}^{2}$.

Os resultados da contagem de mesófilos oriundos de suabes coletados antes e após a higienização foram tabelados e submetidos à análise de variância ANOVA $(p<0,05)$, sendo as médias comparadas pelo teste de tukey para verificação de diferenças significativas, utilizando-se o programa Assistat 7.7 Beta. 


\section{RESULTADOS E DISCUSSÃO}

$\mathrm{Na}$ Tabela 1, estão apresentados os resultados das análises microbiológicas realizadas nas superfícies dos setores da área fria e quente, antes e depois da realização do PPHO do intervalo de almoço.

TABELA 1 - Contagem em placa de mesófilos aeróbios totais obtidos de suabes de superfícies coletados de equipamentos e utensílios da área fria e quente de um matadouro frigorífico.

\begin{tabular}{|c|c|c|}
\hline \multirow{2}{*}{ Superfície equipamentos e utensílios } & \multicolumn{2}{|c|}{ Mesófilos aeróbios (UFC/ $\mathrm{cm}^{2}$ ) } \\
\hline & Antes & Depois \\
\hline Mesa de embalagem primária do dianteiro $A$ & $9,5 \pm 1^{a B}$ & $1,5 \pm 1^{\mathrm{b} A B C}$ \\
\hline Mesa de embalagem primária do dianteiro $B$ & $3,5 \pm 5,74^{a B}$ & $0 \pm 0^{b c}$ \\
\hline Mesa de embalagem primária do traseiro $A$ & $13,5 \pm 2^{\mathrm{a}} \mathrm{B}$ & $0,5 \pm 1^{\mathrm{b} \mathrm{BC}}$ \\
\hline Mesa de embalagem primária do traseiro $B$ & $11,5 \pm 12,89^{a}$ & $0,5 \pm 1^{\mathrm{aBC}}$ \\
\hline Mesa de refile do traseiro $A$ & $26,5 \pm 1,29^{\mathrm{a} A B}$ & $5,5 \pm 3,78^{\mathrm{b} \mathrm{A}}$ \\
\hline Mesa de refile do traseiro $B$ & $8,5 \pm 5,92^{\mathrm{aB}}$ & $1,5 \pm 3^{\mathrm{aABC}}$ \\
\hline Mesa de refile do dianteiro $A$ & $9 \pm 7,5^{\mathrm{aB}}$ & $1,5 \pm 1^{\mathrm{bABC}}$ \\
\hline Mesa de refile do dianteiro $B$ & $10,5 \pm 9,98^{\mathrm{aB}}$ & $3,5 \pm 3,41^{\mathrm{aABC}}$ \\
\hline Mesa de desossa do dianteiro $\mathrm{A}$ & $19,6 \pm 26,65^{\mathrm{aAB}}$ & $0 \pm 0^{\mathrm{bc}}$ \\
\hline Mesa de desossa do dianteiro $B$ & $21 \pm 15,79^{\mathrm{aAB}}$ & $3,5 \pm 1,91^{\mathrm{aABC}}$ \\
\hline Mesa de desossa do traseiro $A$ & $22,5 \pm 16,09$ aAB & $4,5 \pm 1,91^{\mathrm{aAB}}$ \\
\hline Mesa de desossa do traseiro $B$ & $19,5 \pm 9,14^{\mathrm{aAB}}$ & $4 \pm 4$ bABC \\
\hline Serra de quartos & $10,75 \pm 21^{\mathrm{aB}}$ & $0 \pm 0 \mathrm{bc}$ \\
\hline Serra de ponta de agulha & $6 \pm 12^{\mathrm{aB}}$ & $0 \pm 0^{\mathrm{aC}}$ \\
\hline Serra de peito & $0 \pm 0^{\mathrm{a} B}$ & $0 \pm 0^{\mathrm{a} C}$ \\
\hline Centrifuga de miúdos & $0 \pm 0^{\mathrm{a} B}$ & $0 \pm 0^{\mathrm{a} C}$ \\
\hline Esfoladeira & $0 \pm 0^{\mathrm{a} B}$ & $0 \pm 0^{\mathrm{aC}}$ \\
\hline Tanque de resfriamento de buchos & $2 \pm 4^{\mathrm{a} B}$ & $0 \pm 0^{\mathrm{ac}}$ \\
\hline Mesa de vísceras & $7 \pm 5,03^{a \mathrm{~B}}$ & $0 \pm 0^{\mathrm{b} c}$ \\
\hline Centrífuga da bucharia limpa & $22 \pm 25,61^{\text {a } A B}$ & $0 \pm 0^{\mathrm{ac}}$ \\
\hline Mesa de embalar miúdos & $26 \pm 34,44^{\text {a AB }}$ & $0 \pm 0^{\mathrm{a} C}$ \\
\hline Máquina de escorrer tripa & $39 \pm 36,53^{\mathrm{a} A B}$ & $1,5 \pm 1^{\text {a } A B C}$ \\
\hline Mesa de cabeça & $49,5 \pm 21,19^{a A B}$ & $0 \pm 0^{\mathrm{b}} \mathrm{c}$ \\
\hline Mesa de refile de tripas & $69 \pm 55,82^{\mathrm{a} A}$ & $0,50 \pm 1^{\text {b BC }}$ \\
\hline
\end{tabular}

Médias seguidas de letras minúsculas diferentes na mesma linha e médias seguidas de letras maiúsculas diferentes na mesma coluna diferem significativamente $(p<0,05)$ entre si pelo teste de Tukey.

De acordo com EVANCHO et al. (2001), os padrões microbiológicos de superfície devem ser de no máximo $2 \mathrm{UFC} / \mathrm{cm}^{2}$. Ainda de acordo com a Circular 444 de 2006 CGPE/DIPOA para exportação de carne bovina para o Chile (BRASIL, 2006) e com o Regulamento 2073 de 2005 da Comissão das Comunidades Européias para critérios microbiológicos aplicáveis aos gêneros alimentícios, a contagem total de mesófilos aeróbios para suabes de superfícies deve ser $\leq 10$ $\mathrm{UFC} / \mathrm{cm}^{2}$ após o PPHO, sendo este o padrão utilizado (BRASIL, 2005).

Das 96 análises de suabes de superfície realizadas após a higienização durante o intervalo de almoço, todos os resultados obtidos apresentaram contagem inferior a $6 \mathrm{UFC} / \mathrm{cm}^{2}$, estando de acordo com o preconizado pelo regulamento 2073 de 2005, mostrando que a higienização foi eficiente para manutenção dos níveis de contaminação abaixo do limite máximo recomendado. 
PASTRO (2012) encontrou, em pesquisa semelhante, contagem de aeróbios mesófilos após a higienização variando de 0 a $10 \mathrm{UFC} / \mathrm{cm}^{2}$, quando analisou equipamentos como faca, alicate de chifres, lâmina da máquina trimmer, mesa da máquina skinner, mesa de refile e bandeja branca.

Valores mais elevados $\left(3,9\right.$ e $\left.1,7 \mathrm{log} \mathrm{UFC} / \mathrm{cm}^{2}\right)$ foram obtidos por ANDRADE et al. (2005) e ARAUJO et al. (2011) respectivamente, quando analisaram equipamentos de retirar pele e de fatiadores de frios. Estes consideram que tais resultados estão relacionados com o difícil desmonte dos equipamentos e cantos de difícil limpeza, dificultando uma higienização eficaz.

Quando comparados os níveis de contaminação dos equipamentos antes e depois da higienização no intervalo de almoço, observou-se que na área quente apenas três das superfícies analisadas apresentaram redução significativa na contagem de micro-organismos após o procedimento de higienização, os equipamentos foram: mesa de vísceras, mesa de cabeça e mesa de refile de tripas. Quanto aos equipamentos localizados na área fria, pôde-se observar a redução significativa na contagem de mesófilos em seis dos 14 equipamentos analisados, sendo estes a mesa de desossa do traseiro $B$, mesa de desossa do dianteiro $A$, mesa de refile do traseiro $A$, mesa de embalagem primária do traseiro $A$, mesa de embalagem primária do dianteiro $\mathrm{A}$ e a mesa de embalagem primária do dianteiro $\mathrm{B}$.

Embora nos demais equipamentos e utensílios, com exceção da esfoladeira e serra de peito, tenham sido observadas numericamente reduções nas médias da contagem de UFC, estas não diferiram estatisticamente, o que pode ser explicado pelo desvio padrão alto, indicando a necessidade de um estudo posterior no qual sejam realizadas mais repetições na tentativa de reduzir o erro experimental.

A presença de mesófilos após a higienização de equipamentos como a mesa de desossa do dianteiro $B$, mesa de refile do traseiro $A$, mesa de refile do traseiro $B$, mesa de refile do dianteiro $A$, mesa de refile do dianteiro $B$, mesa de desossa do traseiro $A$ e mesa de desossa do traseiro $B$ pode estar relacionada ao fato de que no intervalo de almoço não é realizada lavagem com água quente e o PPHO é procedido somente com um pano perfex e sanitizante.

Um estudo realizado em Porto Alegre em fatiadores de fiambre de hipermercados e supermercados encontrou resultados entre $1 \times 10^{-2} \mathrm{UFC} / \mathrm{cm}^{2}$ e $9 \times 10^{3} \mathrm{UFC} / \mathrm{cm}^{2}$ antes do procedimento de higienização e $0 \mathrm{UFC} / \mathrm{cm}^{2}$ a $1 \times 10^{3}$ $\mathrm{UFC} / \mathrm{cm}^{2}$ após. Demonstrando uma diminuição de mesofilos aeróbios (GOTTARDI, 2006).

PERACHI et al. (2011) realizaram um estudo para avaliar a eficiência dos procedimentos de limpeza e sanitização de facas e tesouras utilizadas na desossa de frangos na cidade de Taquari-RS, em que foram coletadas 32 amostras para a contagem de mesófilos aeróbios. Antes da higienização, as facas apresentaram resultados entre 3 e $69 \mathrm{UFC} / \mathrm{cm}^{2}$ e após esta, todos apresentaram contagem menor que $1 \mathrm{UFC} / \mathrm{cm}^{2}$. Para a tesoura, os resultados foram de 1 a $46 \mathrm{UFC} / \mathrm{cm}^{2}$ e menor que $1 \mathrm{UFC} / \mathrm{cm}^{2}$ antes e depois da higienização, respectivamente.

SILVA (2006) realizou um estudo em uma unidade de alimentação para verificar o procedimento de higienização de utensílios, equipamentos e mãos de manipuladores utilizando a técnica suabe, no qual foram investigados os microorganismo mesofilos aeróbios, bolores, leveduras, coliformes totais e coliformes tolerantes a $45^{\circ}$. Após a higienização, os resultad os foram satisfatórios obtendo-se contagem inferior a $1 \mathrm{UFC} / \mathrm{cm}^{2}$. Esses resultados comprovam que os procedimentos 
padrões de higiene operacional quando realizados de forma adequada mostram-se eficientes na redução da carga microbiana de mesófilos aeróbios.

Ao realizar comparação das médias de contagem de mesófilos entre os equipamentos e utensílios antes da higienização, pôde-se observar que a mesa de refile de tripas $\left(69 \mathrm{UFC} / \mathrm{cm}^{2}\right)$, mesa da cabeça $\left(49,5 \mathrm{UFC} / \mathrm{cm}^{2}\right)$, máquina de escorrer tripa (39 UFC/ $\left.\mathrm{cm}^{2}\right)$, mesa de refile do traseiro $A\left(26,5 \mathrm{UFC} / \mathrm{cm}^{2}\right)$, mesa de embalar (26 UFC/ $\left./ \mathrm{cm}^{2}\right)$, mesa de desossa do traseiro A $\left(22,5 \mathrm{UFC} / \mathrm{cm}^{2}\right)$, mesa de desossa do dianteiro A (22,5 UFC/ $\left.\mathrm{cm}^{2}\right)$, centrífuga da bucharia limpa (22 UFC/cm²), mesa de desossa do dianteiro $B\left(21 \mathrm{UFC} / \mathrm{cm}^{2}\right)$ e mesa de desossa do traseiro $\mathrm{B}(19,5$ $\mathrm{UFC} / \mathrm{cm}^{2}$ ) apresentaram maior nível de contaminação, tendo a mesa de refile de tripas apresentado numericamente a maior contagem de UFC/cm ${ }^{2}$. Este resultado pode ser justificado pelo fato das tripas serem naturalmente mais contaminadas, por possuírem conteúdo gastrointestinal. A contaminação das tripas é previsível devido à limpeza destas ser realizada em água a temperatura ambiente $\left( \pm 37^{\circ} \mathrm{C}\right)$, sendo favorável para o desenvolvimento de mesófilos (PARDI et al., 2001).

Os equipamentos como a mesa de embalagem primária do traseiro $A(13,5$ $\left.\mathrm{UFC} / \mathrm{cm}^{2}\right)$, mesa de embalagem primária do traseiro $\mathrm{B}\left(11,5 \mathrm{UFC} / \mathrm{cm}^{2}\right)$, serra de quartos $\left(10,75 \mathrm{UFC} / \mathrm{cm}^{2}\right)$, mesa de refile do dianteiro $\mathrm{B}\left(10,5 \mathrm{UFC} / \mathrm{cm}^{2}\right)$, mesa de embalagem primária do dianteiro $\mathrm{A}\left(9,5 \mathrm{UFC} / \mathrm{cm}^{2}\right)$, mesa de refile do dianteiro $\mathrm{A}(9$ $\left.\mathrm{UFC} / \mathrm{cm}^{2}\right)$, mesa de refile do traseiro $\left(8,5 \mathrm{UFC} / \mathrm{cm}^{2}\right)$, mesa de víscera $\left(7 \mathrm{UFC} / \mathrm{cm}^{2}\right)$, serra de ponta de agulha (6 UFC/ $\left./ \mathrm{cm}^{2}\right)$, mesa de embalagem primária do dianteiro $\mathrm{B}$ $\left(3,5 \mathrm{UFC} / \mathrm{cm}^{2}\right)$, tanque de resfriamento $\left(2 \mathrm{UFC} / \mathrm{cm}^{2}\right)$, centrífuga dos miúdos (0 UFC $/ \mathrm{cm}^{2}$ ), esfoladeira $\left(0 \mathrm{UFC} / \mathrm{cm}^{2}\right)$ e serra de peito $\left(0 \mathrm{UFC} / \mathrm{cm}^{2}\right)$ apresentaram menor número de contagem de mesófilos antes da higienização.

A ausência de contaminação na serra de peito e esfoladeira, tanto antes quanto após a higienização, pode ser explicada pelo fato destes equipamentos serem esterilizados em água quente, a uma temperatura de pelo menos $82,5^{\circ} \mathrm{C}$, após o corte e a esfola de cada animal, dificultando o desenvolvimento de microorganismos. O baixo nível de contaminação encontrado na centrífuga dos miúdos e do tanque de resfriamento pode ser explicado pela utilização de água quente e água fria $\left( \pm 10^{\circ} \mathrm{C}\right)$, sendo estas temperaturas desfavorávei s à proliferação de mesófilos aeróbios.

Os equipamentos: serra de quartos e serra de ponta de agulha (PA) eram higienizados com água a $82,5^{\circ} \mathrm{C}$ a cada três horas, j ustificando a baixa contagem de UFC $/ \mathrm{cm}^{2}$ antes do PPHO. Quando comparados os níveis de contaminação dos utensílios e equipamentos após a realização do $\mathrm{PPHO}$, verificou-se que a mesa de refile do traseiro $A$ mostrou-se mais contaminada. Como as peças do traseiro possuem mais gordura do que as peças do dianteiro, consequentemente, deixam mais resíduos de gordura sobre as superfícies destas. E pelo fato do PPHO de intervalo do almoço do setor de desossa não ser realizado com a utilização de água quente, tendendo a tornar mais difícil a remoção da gordura, facilitando a permanência de contaminantes aderidos à superfície.

Vale considerar que as condições higiênicas sob a quais os animais adentram para o abate também interferem nas condições microbiológicas, sendo que algumas etapas colaboram para o aumento da carga microbiana em superfícies de contato com o alimento (MATSUBARA, 2005). 


\section{CONCLUSÃO}

O presente estudo de monitoramento da higienização de equipamentos e utensílios de um matadouro frigorífico bovino permitiu concluir que:

Houve redução na contagem de mesófilos após o procedimento de higienização dos equipamentos e utensílios, demonstrando sua eficácia.

A sanitização realizada com água quente apresentou melhores resultados na redução da contagem de micro-organismos, quando comparado ao ácido peracético, obtendo-se menores contagens ao final do processo.

Os resultados das análises microbiológicas das diversas superfícies de contato, coletadas após o procedimento de higienização, apresentaram médias de contagem inferiores a $6 \mathrm{UFC} / \mathrm{cm}^{2}$, estando em acordo com o Regulamento $2073 \mathrm{de}$ 2005 da Comissão das Comunidades Europeias, demonstrando a conformidade do Procedimento Padrão de Higiene Operacional (PPHO) do intervalo de almoço. Comprovando sua eficiência em reduzir e manter a níveis toleráveis de contaminação, minimizando os riscos à saúde dos consumidores.

\section{REFERÊNCIAS}

ANDRADE, N. J; ARAÚJO, E. A; CAMILLOTO, G. P; PIRES A. C; RIBEIRO M. C. T; SOARES, N. F. F. Condições higiênicas de fatiadores de frios avaliadas por ATP bioluminescência e contagem microbiana: sugestão de higienização conforme RDC 275 da ANVISA. Alimentos e Nutrição. Araraquara, v. 16, n.2, p. 123-129, 2005.

AOAC- OFICIAL METHODS OF ANALYSIS. Microbiological examination of foods - Edição 18 , 2007.

ARAUJO, E. A. F.; LOURENÇO, L. F. H.; SOUSA, C. L.; SOUZA, J. N. S. Avaliação da qualidade microbiológica no processamento de pescados. Revista Instituição Rodolfo Lutz. São Paulo, v.70, n.2, p. 151-7, 2011.

BORGES, J.T. da S.; FREITAS, A.S. Aplicação do sistema hazard analysis and critical control points (haccp) no processamento de carne bovina fresca. B.CEPPA, Curitiba, v. 20, n. 1, p. 1-18, 2002.

BRASIL. Circular no 444, 28 de junho de 2006. Exportação de carne bovina para o Chile. Diário oficial [da] União, Brasília, DF, 28 jun 2006.

BRASIL. Regulamento (CE) no 2073/2005 da Comissão das Comunidades Europeias, de 15 de novembro de 2005. Critérios microbiológicos aplicáveis aos gêneros alimentícios. Diário Oficial [da] União, 16 de maio 2005.

BRASIL. Ministério da Agricultura, Pecuária e Abastecimento. Mercado interno. 2014. Disponível em: < http://www.agricultura.gov.br/animal/mercado-interno>. Acesso em: 01 de maio 2014.

CONAB. Perspectiva para as carnes bovina, de frango e suína 2013-2014. 2014. Disponível em: <http://www.conab.gov.br/OlalaCMS/uploads/arquivos/13_09_12_17_43_13_09_car nes.pdf>. Acesso em: 01 de maio 2014. 
EVANCHO, G.M.; SVEUM, W.H.; MOBERG, L.J. Bacillus cereus. In: Downes FD, Ito $\mathrm{K}$, editors. Compendium of methods for the microbiological examination of foods. 4 . Ed. Washington, D.C.: APHA, 2001, p.311-316.

GOTTARDI, C. P. T. Avaliação das condições higiênico-sanitarias do ambiente de manipulação de produtos fatiados de origem animal de redes de supermercados de Porto Alegre. 2006. 80f. Dissertação, Universidade Federal do Rio Grande do Sul, Porto Alegre, 2006.

IBGE. Indicadores IBGE: Estatística da produção pecuária. 2013. Disponível em: $<$ http://www.ibge.gov.br/home/estatistica/indicadores/agropecuaria/producaoagropec uaria/abate-leite-couro-ovos_201303_publ_completa.pdf>. Acesso em: 02 de maio 2014.

JAY, J. M. Microbiologia dos alimentos. 6ed. Porto Alegre: Artmed, 2005.

OLIVEIRA, D.L., PINHEIROS, E.; RAYMUNDI, G.L.; MOREIRA, P.C.; MAGALHÃES, R.T.; WASCHECK, R. DE C. Análise de perigos e pontos críticos de controle em processamento de abate de bovinos. Estudos. Goiânia, v.36. p.611-636, 2009.

PERACHI, J.; CAVALLERI, R.; SOUZA, C.F.V. Monitoramento da higienização de facas e tesouras utilizadas na desossa de frangos em um frigorífico do vale do Taquari/RS. Interbio. v.5, n.2, 2011

MATSUBARA, E.N. Condição higiênico-sanitária de meias carcaças de suínos após o abate e depois do resfriamento e analise da utilização da lista de verificação para avaliar boas práticas no abate suíno. 2005.154p. Universidade de São Paulo. 2005.

PARDI, M.C.; SANTOS, I.F.; SOUZA, E.F.; PARDI, H.S. Ciência, Higiene e Tecnologia da Carne. Volume I. $1^{\circ}$ Ed. (reimpressão). Goiânia: CEGRAF-U FG/ EDUFF, 2001.

PASTRO, D. Validação do Procedimento do Padrão de Higiene Operacional (PPHO): Estudo de caso em um frigorifico bovino do Estado do Mato Grosso. 2012. 50p. Monografia apresentada como pré-requisito para conclusão do Curso de Engenharia de Alimentos, Universidade Estadual do Mato Grosso, Barra do Bugres, 2012.

SILVA, L.F. Procedimento Operacional Padronizado de Higiene como requisito para a segurança alimentar em Unidade de Alimentação. 2006. 70p. Dissertação apresentada ao Curso de Mestrado em Ciência e Tecnologia de Alimentos, da Universidade Federal de Santa Maria, Santa Maria, 2006. 